\title{
Characterization of Partial Resistance to Black Spot Disease of Rosa sp.
}

\author{
Qianni Dong \\ Department of Horticultural Sciences, Texas A\&M University, College \\ Station, TX 77843
}

\author{
Xinwang Wang \\ Southern Plains Agricultural Research Center, USDA-ARS, College Station, \\ TX 77845
}

\author{
David H. Byrne ${ }^{1}$ \\ Department of Horticultural Sciences, Texas A\&M University, College \\ Station, TX 77843
}

\section{Kevin Ong \\ Department of Plant Pathology and Microbiology/Bioenvironmental Sciences, Texas A\&M University, College Station, TX 77843}

Additional index words. Rosa wichuraiana, fungus, Diplocarpon rosae, horizontal resistance, rose, detached leaf assay, disease resistance

\begin{abstract}
Black spot disease, caused by the fungus Diplocarpon rosae Wolf, is one of the most serious diseases of garden roses. Both complete (vertical) resistance conditioned by dominant $\boldsymbol{R} \boldsymbol{d} \boldsymbol{r}$ genes and partial (horizontal) resistance conditioned by multiple genes have been described. The use of resistant rose cultivars would reduce the demand of agrochemical applications. The characterization of 16 genotypes for resistance to black spot using two laboratory assays, the detached leaf assay (DLA) and the whole plant inoculation (WPI) approach, indicated that these techniques were well correlated. Thus, either method could be used to assess the resistance of the plants to black spot. Fifteen diploid hybrid populations from 10 parents segregating for partial (horizontal) resistance to black spot derived from Rosa wichuraiana 'Basye's Thornless' (RW) were assessed for black spot resistance by quantifying the percentage of the leaf area with symptoms (LAS) and lesion length (LL) measured by the diameter of the largest lesion per leaf in DLAs. The narrow-sense heritability of partial resistance to black spot as measured by LAS and LL data of DLA was estimated to be from 0.28 to 0.43 when calculated with a genetic variance analysis and from 0.74 to 0.86 when generated from offspring-midparent regression. This suggests that the development of rose cultivars with high levels of stable partial resistance to black spot is a feasible approach for the rose industry.
\end{abstract}

Roses, which are distributed throughout the temperate regions of the Northern Hemisphere (Krüssmann, 1981), have been important ornamental plants for more than 5000 years. There are thousands of cultivars for the garden, floriculture, medicinal, fragrance, and culinary industries (Gudin, 2000; Marriott, 2003; Shepherd, 1954). The rose industry contributes a value of about $\$ 400$ million from garden roses, which is the major crop in the $\$ 2.81$ billion

Received for publication 12 Sept. 2016. Accepted for publication 17 Nov. 2016.

This work was partially funded by Monsanto Fellows in Plant Breeding program, the Robert E. Basye Endowment in Rose Genetics, and the USDA's National Institute of Food and Agriculture (NIFA) Specialty Crop Research Initiative project, "RosBREED: Combining disease resistance with horticultural quality in new Rosaceous cultivars." We thank the Hokanson lab at the University of Minnesota for supplying race 8 of Diplocarpon rosae used in this work.

${ }^{1}$ Corresponding author. E-mail: dbyrne@tamu.edu. around the lesion and eventually defoliation (Blechert and Debener, 2005; Gachomo et al., 2006; Horst and Cloyd, 2007). Eleven unique races of $D$. rosae have been identified among the isolates obtained from North America and Europe (Whitaker et al., 2010b).

Two types of disease resistance to black spot have been characterized in roses. Vertical or complete resistance, which blocks sporulation and severely restricts the mycelial growth of the pathogen, is usually controlled by major dominant genes ( $R d r$ or Rosa disease resistance genes) (von Malek and Debener, 1998; Whitaker et al., 2010a; Yokoya et al., 2000). In rose, the dominant resistance genes are pathogen race-specific, indicating a gene-for-gene interaction pattern (von Malek and Debener, 1998).

Partial or horizontal resistance that appears to be non-race-specific has also been identified in roses (Shupert, 2005; Whitaker and Hokanson, 2009a, 2009b; Xue and Davidson, 1998). This resistance does not prevent infection of the pathogen, but rather delays disease development and results in reduced lesion size, reduced sporulation, and/or delayed infection after inoculation (Parlevliet, 1981; Whitaker and Hokanson, 2009a, 2009b; Xue and Davidson, 1998). Compared with complete resistance, partial resistance is generally more durable over the range of pathogenic races (Noack, 2003). The ideal disease-resistant genotype should have both highly effective and long-lasting resistance to a broad spectrum of pathogenic races (Blechert and Debener, 2005), which can be achieved by pyramiding dominant complete resistance genes, obtaining strong partial resistance or by combining both types of resistances.

Black spot resistance is commonly evaluated in field trials in different geographic regions to expose the rose to a greater number of pathogenic races. These trials typically last 2-3 years to ensure sufficient disease pressure to properly assess the resistance of the plants (Carlson-Nilsson, 2002; Debener and Byrne, 2014; Noack, 2003; Shupert, 2005). The laboratory-based DLA is a tool for observing disease development efficiently under uniform and well-controlled environmental conditions and inoculum levels (Hattendorf et al., 2004; von Malek and Debener, 1998; Whitaker and Hokanson, 2009a, 2009b). Because single-conidial isolates are used in laboratory screening, the combination of compatible and incompatible interactions that are caused by various races in nature can be avoided (Blechert and Debener, 2005). However, as DLA only allows one cycle of disease development, the differences among genotypes might not be as accentuated as compared with a field trial in which multiple cycles of pathogen development are common (Xue and Davidson, 1998). Other factors such as the physical status of the host plant, degradation of the leaves, missing observations on leaf abscission/defoliation in DLA, and low or nonuniform inoculation levels in field assessment could all cause low correlation between these two methods of 
phenotyping (Johansson et al., 1992; Palmer et al., 1966; Zlesak et al., 2010).

The objectives of this research were to 1) evaluate two methods (DLA and WPI) of artificial inoculation for black spot disease evaluation and characterize rose genotypes for black spot resistance and 2) characterize partial black spot disease resistance derived from RW in laboratory tests in diploid populations to estimate the components of genetic variances, and the heritability of this partial resistance.

\section{Materials and Methods}

Plant materials. Based on previous field ratings for black spot resistance, seven black spot-susceptible roses ['Cal Poly' (Cal), 'Golden Gardens', 'Orange Honey' (OH), 'Red Fairy' (RF), 'Sweet Chariot' (SC), 'Vineyard Song' (VS), and 'Violette'], one with moderate resistance ('Old Blush'), seven black spot-resistant breeding lines (91/100-5, DD, FF, J06-20-14-3, J06-28-46, J06-30-3-6, M4-4, and one rose species RW) were propagated from cuttings and grown in 1-gal pots containing a growth media of decomposed pine bark amended with Metro-Mix growing media ${ }^{\circledR}$ (Sun Gro Horticulture Canada CM Ltd, Agawam, WA) under the greenhouse environment for 3 months before the experiments (Byrne et al., 2010; Zlesak et al., 2010). Nine individuals were randomly selected from each genotype for artificial inoculation for black spot resistance evaluation. The experiment was repeated three times.

Fifteen diploid populations were generated in an incomplete diallel mating design by crossing five black spot-resistant lines [J06-20-14-3 (J14-3), J06-28-4-6 (J4-6), J0630-3-3 (J3-3), J06-30-3-6 (J3-6), M4-4] and a moderately resistant line ('Old Blush') with four susceptible roses ['Little Chief', RF, SC, and VS] to create $F_{1}$ populations segregating for black spot resistance (Table 1). The ploidy level of the parental lines was determined by chromosome counts. All the resistant lines have black spot resistance derived from RW. These were developed by crossing RW with either 'Old Blush' or 'Ducher' and then selecting among the $F_{2}$ and $\mathrm{F}_{3}$ populations created by open pollination for high black spot resistance, recurrent bloom, and a high number of flowers. The moderately resistant and susceptible parents are commercial roses with excellent ornamental characteristics. All populations were maintained as either the original seedlings or clonal cuttings from the original seedling in 1-gal pots as previously described. At the age of 2 months, the plants were pruned back to synchronize shoot development to obtain shoots of similar physiological stage for inoculation. The pruning procedure was applied each time after collecting leaf samples.

Inoculation and data collection. Race 8 (also known as ACT) of D. rosae, originally collected in Brenham, TX, (Whitaker et al., $2010 \mathrm{~b}$ ) was selected as the pathogen race to use for the evaluation of partial resistance because the parents in this project showed partial resistance but not complete resistance to race 8 . Thus, they do not contain $R d r 3$ vertical resistance gene to race 8 . Conidia of race 8 of $D$. rosae (supplied by the Hokanson laboratory at the University of Minnesota) was collected by washing the infected leaves of ' $\mathrm{Cl}$. Pinkie' with distilled (DI) water. The concentration of the conidia was adjusted to $1 \times 10^{5}$ conidia $/ \mathrm{mL}$ with a hemocytometer (Whitaker and Hokanson, 2009a; Whitaker et al., 2010a).

Detached leaf assay. From each plant in an individual pot, up to seven fully expanded young compound leaves (fourth to sixth nodes from apex of each shoot) were collected for each replication. After washing with DI (distilled) water for $10 \mathrm{~s}$ on each side, the seven leaves were placed on wet paper towels in a transparent plastic container $(152 \times 140 \times 59 \mathrm{~mm})$. The conidia suspension $\left(0.75 \mathrm{~mL}\right.$ of $1 \times 10^{5}$ conidia $\left./ \mathrm{mL}\right)$ was sprayed onto the leaves from a distance of $20-30 \mathrm{~cm}$ to generate fine mist, left for $48 \mathrm{~h}$, and then residual water was removed by blotting. The droplet method was not used because it tended to cause leaf degradation. DI water was added to the paper towel without direct contact with the leaves to maintain the humidity in the boxes at $100 \%$. The inoculated leaves were then maintained in the laboratory $\left(\approx 25{ }^{\circ} \mathrm{C}\right.$ and 10 -h photoperiod $)$ for 14-16 d and then inspected for the incidence of acervuli under the dissecting microscope. The LAS (percentage of leaf area with symptoms) and LL (diameter of the largest individual lesion) data were collected. Although other components such as incubation period, number of lesions, and sporulation capacity could all be used to characterize the disease resistance ability, LAS and LL were chosen here due to their high linear correlations and low-labor requirements which make them appropriate for massive screening of breeding materials (Xue and Davidson, 1998). All evaluations for the rose genotype comparison and the seedling evaluations were repeated three times.

Whole plant inoculation. Three plants of each genotype with branches of a similar size

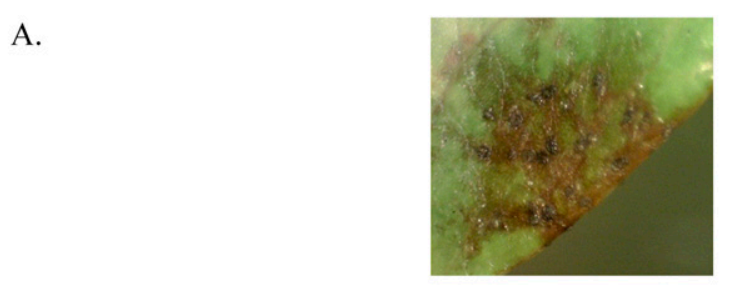

B.
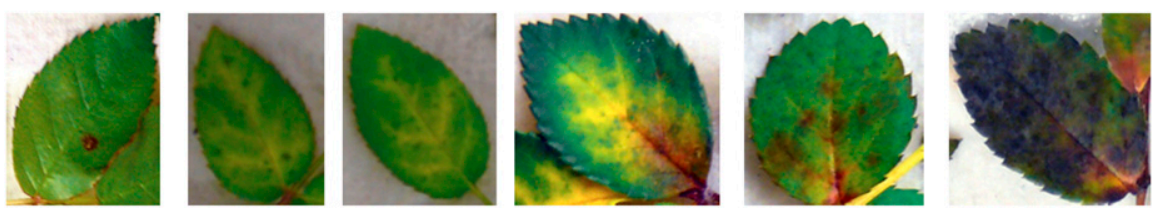

Fig. 1. (A) Spores bearing acervuli on infected leaf surface of ' $\mathrm{Cl}$. Pinkie'. (B) Diagrammatic representation of leaf area with symptoms of black spot disease at $1 \%, 5 \%, 10 \%, 25 \%, 50 \%$, or $75 \%$ in detached leaf assay. were selected and sprayed with a conidial suspension $\left(1 \times 10^{5}\right.$ conidia $\left./ \mathrm{mL}\right)$ until the leaf surface was completely wet. The wet tissue was then covered with a plastic bag that was sealed around the stem for 1 week. Additional DI water was sprayed into the bags for highhumidity $(100 \%)$ maintenance. The inoculated plants were then maintained in the laboratory $\left(\approx 25{ }^{\circ} \mathrm{C}, 10\right.$-h photoperiod with a humidifier) under cool white florescence lights (2150 lumens, Sylvania Fluorescent MA). Four weeks after inoculation, acervuli incidence was checked under the dissecting microscope. LAS and LL data under WPI were collected on various leaves since the leaf size varied among breeding lines for similar biomass. Each plant generated one data point. The entire experiment was repeated three times.

Partial resistance was measured by the diameter of the largest individual lesion (LL) and the percentage of LAS. The visual rating score of the leaf area with lesions was as

Table 1. Parents ${ }^{\mathrm{z}}$, parental black spot resistance ${ }^{\mathrm{y}}$, and population size of the diploid rose populations used in the genetic study.

\begin{tabular}{lcc}
\hline Female parent & Pollen parent & Population size \\
\hline J14-3 (HR) & SC (S) & 57 \\
SC (S) & J14-3 (HR) & 58 \\
J14-3 (HR) & LC (S) & 140 \\
J14-3 (HR) & RF (S) & 130 \\
J14-3 (HR) & VS (S) & 93 \\
VS (S) & J14-3 (HR) & 12 \\
M4-4 (HR) & SC (S) & 26 \\
SC (S) & M4-4 (HR) & 118 \\
M4-4 (HR) & VS (S) & 10 \\
J4-6 (HR) & RF (S) & 97 \\
SC (S) & J4-6 (HR) & 23 \\
OB (MR) & J3-6 (HR) & 112 \\
OB (MR) & M4-4 (HR) & 54 \\
OB (MR) & RF (S) & 158 \\
J3-3 (HR) & RF (S) & 38 \\
\hline
\end{tabular}

${ }_{\mathrm{Z}} \mathrm{J} 14-3=\mathrm{J} 06-20-14-3 ; \mathrm{J} 4-6=\mathrm{J} 06-28-4-6 ; \mathrm{J} 3-3=$ J06-30-3-3; J3-6 = J06-30-3-6; OB = 'Old Blush'; $\mathrm{LC}=$ 'Little Chief'; RF = 'Red Fairy'; $\mathrm{SC}=$ 'Sweet Chariot'; VS = 'Vineyard Song'.

${ }^{y_{S}}$ = susceptible; $M R=$ medium resistance; $\mathrm{HR}=$ high resistance. Light Bulb SL21371; Sylvania, Wilmington, 
Table 2. Least square means of black spot leaf area with symptoms (LAS) and black spot lesion length (LL) for 16 rose genotypes after infection with race 8 of Diplocarpon rosae with the detached leaf assay (DLA) and whole plant inoculation (WPI).

\begin{tabular}{|c|c|c|c|c|c|}
\hline \multirow[b]{3}{*}{ Genotype $^{\mathrm{y}}$} & \multicolumn{5}{|c|}{ Least square means ${ }^{z}$} \\
\hline & \multicolumn{2}{|c|}{ DLA } & \multicolumn{3}{|c|}{ WPI } \\
\hline & LAS & $\overline{L L}$ & $\mathrm{NF}$ & LAS & LL \\
\hline$\overline{91 / 100-5}$ & $1.50 \mathrm{bcdef}$ & $2.00 \mathrm{abcde}$ & $0.00 \mathrm{bz}$ & $1.00 \mathrm{~b}$ & $2.00 \mathrm{abc}$ \\
\hline $\mathrm{Cal}$ & 1.98 abcde & $2.33 \mathrm{abcd}$ & $0.00 \mathrm{~b}$ & $1.11 \mathrm{~b}$ & $4.06 \mathrm{a}$ \\
\hline DD & $1.00 \mathrm{f}$ & $1.03 \mathrm{cde}$ & $0.22 \mathrm{ab}$ & $1.00 \mathrm{~b}$ & $1.46 \mathrm{bc}$ \\
\hline $\mathrm{FF}$ & 1.75 abcde & $1.25 \mathrm{cde}$ & $0.56 \mathrm{ab}$ & $1.67 \mathrm{ab}$ & $1.43 \mathrm{bc}$ \\
\hline GG & $2.08 \mathrm{abcd}$ & $2.50 a b c$ & $0.22 \mathrm{ab}$ & $1.89 \mathrm{ab}$ & $3.39 \mathrm{ab}$ \\
\hline J14-3 & $1.28 \mathrm{cdef}$ & $1.15 \mathrm{cde}$ & $0.56 \mathrm{ab}$ & $1.56 \mathrm{ab}$ & $1.56 \mathrm{bc}$ \\
\hline J4-6 & $1.08 \mathrm{f}$ & $0.49 \mathrm{e}$ & $0.00 \mathrm{~b}$ & $1.00 \mathrm{~b}$ & $0.70 \mathrm{c}$ \\
\hline $\mathrm{J} 3-6$ & $1.23 \mathrm{def}$ & $1.46 \mathrm{cde}$ & $0.83 \mathrm{a}$ & $1.75 \mathrm{ab}$ & $1.50 \mathrm{bc}$ \\
\hline M4-4 & $1.11 \mathrm{ef}$ & 0.86 cde & $0.11 \mathrm{~b}$ & $1.56 \mathrm{ab}$ & $2.11 \mathrm{abc}$ \\
\hline OB & $1.47 \mathrm{cdef}$ & 1.81 bcde & $0.22 \mathrm{ab}$ & $1.67 \mathrm{ab}$ & $2.83 \mathrm{abc}$ \\
\hline $\mathrm{OH}$ & $2.46 \mathrm{ab}$ & $3.29 \mathrm{ab}$ & $0.78 \mathrm{a}$ & $2.44 \mathrm{a}$ & $2.58 \mathrm{abc}$ \\
\hline RW & $1.46 \mathrm{cdef}$ & $0.51 \mathrm{de}$ & $0.00 \mathrm{~b}$ & $1.17 \mathrm{~b}$ & $1.02 \mathrm{c}$ \\
\hline $\mathrm{RF}$ & $2.53 \mathrm{a}$ & $3.44 \mathrm{ab}$ & $0.40 \mathrm{ab}$ & $1.56 \mathrm{ab}$ & $2.44 a b c$ \\
\hline $\mathrm{SC}$ & $2.49 \mathrm{ab}$ & $3.89 \mathrm{a}$ & $0.56 \mathrm{ab}$ & $1.89 \mathrm{ab}$ & $2.28 \mathrm{abc}$ \\
\hline VS & $2.17 a b c$ & $2.50 a b c$ & $0.78 \mathrm{a}$ & $1.56 \mathrm{ab}$ & $2.06 \mathrm{abc}$ \\
\hline Vio & $1.13 \mathrm{def}$ & $1.25 \mathrm{cde}$ & $0.50 \mathrm{ab}$ & $1.33 \mathrm{~b}$ & $2.81 \mathrm{abc}$ \\
\hline
\end{tabular}

${ }^{\mathrm{z}}$ Least square means within the components connected by the same letter are not significantly different at $P=0.05$, with Student-Newman Kuels adjustment for LAS and LL.

${ }^{\mathrm{y}} \mathrm{J} 14-3$ = J06-20-14-3; J4-6 = J06-28-4-6; J3-3 = J06-30-3-3; J3-6 = J06-30-3-6; RW = Rosa wichuraiana 'Basye's Thornless'; $\mathrm{Cal}=$ = 'Cal Poly'; GG = 'Golden Garden'; Vio = 'Violette'; $\mathrm{OB}=$ 'Old Blush'; $\mathrm{OH}=$ 'Orange Honey'; RF = 'Red Fairy'; SC = 'Sweet Chariot'; VS = 'Vineyard Song'; NF = number of fallen leaves.

Table 3. Correlation coefficients relating the number of fallen leaves (NF), leaf area with symptoms (LAS), and black spot lesion length (LL) from whole plant inoculation (WPI) and LAS and black spot LL from the detached leaf assay (DLA).

\begin{tabular}{|c|c|c|c|c|c|}
\hline & \multicolumn{3}{|c|}{ WPI } & DLA \\
\hline & & $\mathrm{NF}$ & LAS & $\overline{\mathrm{LL}}$ & LAS \\
\hline$\overline{\text { WPI }}$ & LAS & $0.68^{* *}$ & & & \\
\hline & LL & -0.08 & 0.27 & & \\
\hline DLA & LAS & 0.39 & $0.58^{*}$ & 0.46 & \\
\hline & LL & 0.34 & $0.58^{*}$ & $0.56^{*}$ & $0.91^{* * *}$ \\
\hline
\end{tabular}

$*, * *, * * *$ Significant at $P<0.05,0.01$, and 0.001 , respectively (15 df)

follows: 1 for $10 \%, 2$ for $20 \%, 3$ for $30 \%, 4$ for $40 \%$, and 5 for $50 \%$ and above for the screening of the parents that had diverse genetic backgrounds. For phenotyping the progenies of hybrid populations with similar genetic background, LAS scores were categorized as $1 \%, 5 \%, 10 \%, 25 \%, 50 \%$, or $75 \%$ and above to detect the smaller differences of resistance among them (Fig. 1).

Statistical analysis. All the boxes in DLA revealed successful inoculation with infected leaves although occasionally not all leaves showed symptoms or were severely degraded. Data were only collected on the leaves that developed symptoms and were not severely degraded to ensure the data quality. The mean LAS and LL was calculated for each box and the single value was used in further analysis. The statistical analysis was conducted by using JMP software, Version 10, and SAS software 9.3 (SAS Institute Inc., Cary, NC, 1989-2010). The normality and skewness of the population data (original and square root transformed) was analyzed by Kolmogorov-Smirnov (K-S) test (Razali and Wah, 2011), which indicated that a square root transformation improved normality and decreased skewness. Linear correlation of LL and LAS was estimated by Pearson correlation method.

Genetic variances were calculated using the restricted maximum likelihood (REML) method, assuming all factors from this unbalanced design as random effects (Dieters et al., 1995; Holland et al., 2003; Littell et al., 1996). Variances of parents were considered as additive variance $\left(V_{\mathrm{A}}\right)$ and variances of progeny $\left(V_{\mathrm{P}}\right)$ were considered as nonadditive variance $\left(V_{\mathrm{D}}\right)$ (Connor et al., 2005). Narrowsense heritability $\left(h^{2}\right)$ was estimated by the genetic variance from the REML model, where $h^{2}=V_{\mathrm{A}} / V_{\mathrm{P}}$ (Hallauer et al., 2010).

Narrow-sense heritability was also estimated by an offspring-midparent regression (Connor et al., 2005), where $h^{2}=b=\operatorname{cov}(\mathrm{O}$, MP)/cov(MP) (Falconer and Mackay, 1996), i.e., the slope of the regression is then the estimation of heritability, with $R^{2}$ indicating the fitness of the regression.

\section{Results}

Phenotyping of parental materials. Sporebearing acervuli were observed on all parental genotypes whether using the DLA or WPI method, indicating that complete resistance to race 8 of $D$. rosae did not exist among the selected rose genotypes. Using LL and LAS data, the most resistant genotypes as determined by field observations (RW, M4-4, and J4-6) were clearly distinguishable from the roses rated as most susceptible to $D$. rosae (RF, SC, Cal, VS, and OH) (Table 2). The best resolution among rose genotypes was with the LAS data, which was also able to separate other field-resistant roses (91/100-5, DD, J3-6) from the susceptible genotypes. LAS data indicated that the highest rating is 2.46 and 2.44 obtained from OH from DLA and WPI, respectively, either due to the resistance ability from the breeding lines selected for this study or the pathogenesis ability of race 8 . Although various resistant abilities could be revealed by different measurement components, the trending of susceptibility indicated by artificial inoculation is similar to what has been observed in the field. Since partial resistance is a continuous trait, clearly defining a germplasm as resistant or susceptible material might not be practical. The two measures of resistance, LAS and LL, are well correlated $(R=0.91$ at $P<0.0001$; Fig. 2). Genotypes with a higher percentage of LAS being covered with lesions showed longer LL, indicating either of these two traits could be used as an indicator of the host plant response to the pathogen.

When using the WPI to quantify the black spot resistance of the genotypes, it was found that the rose genotypes with higher resistance generally had lower LAS, LL, and number of fallen leaves (NF) when compared with the most susceptible rose genotypes, but these groups were not consistently different (Table 2). This would suggest that the DLA approach is the better method for quantifying the relative partial resistance of rose to black spot. The various measures of black spot, LAS and LL, are generally correlated between DLA and WPI ( $R$ ranging from 0.46 to $0.58)$. With the WPI approach, although NF was correlated with LL, LL and LAS were not correlated. LAS and LL data from DLA were well correlated (Table 3). The significant correlation between DLA and WPI, revealed by this study ( $R$ ranging from 0.56 to 0.58 ), is slightly weaker than the research conducted by Whitaker and Hokanson (2009a), which may be due to the different genetic background of the materials used for screening or inoculation methods such as growth conditions and the races of $D$. rosae that were selected.

Disease distribution of diploid populations. Based on the results of $\mathrm{K}-\mathrm{S}$ normality test, the LL and LAS data normality improved and skewness generally decreased after a square root transformation. Thus, all subsequent statistical analyses were done with the transformed data, but it should be noted that the conclusions reached with the untransformed data and transformed data were not different

Correlations among resistance assessments. The correlation of individual progenies' partial resistance to black spot race 8 measured by LAS and LL (squareroot-transformed data) from the detached leaf tests is $0.3(P<0.0001)$ (Fig. 3). The correlation of these two components was much higher $(R=0.9)$ when estimating among resistant and susceptible parental materials, probably due to the smaller range of resistance among the seedlings vs. parents as measured by LL $(0.5-3.0 \mathrm{~mm}$ vs. $0.1-7.14 \mathrm{~mm}$ ).

Genetic variation and estimation of heritability of disease assessments using the $D L A$. In this incomplete diallel mating design, narrow-sense heritability (additive variance/phenotypic variance) was estimated to 


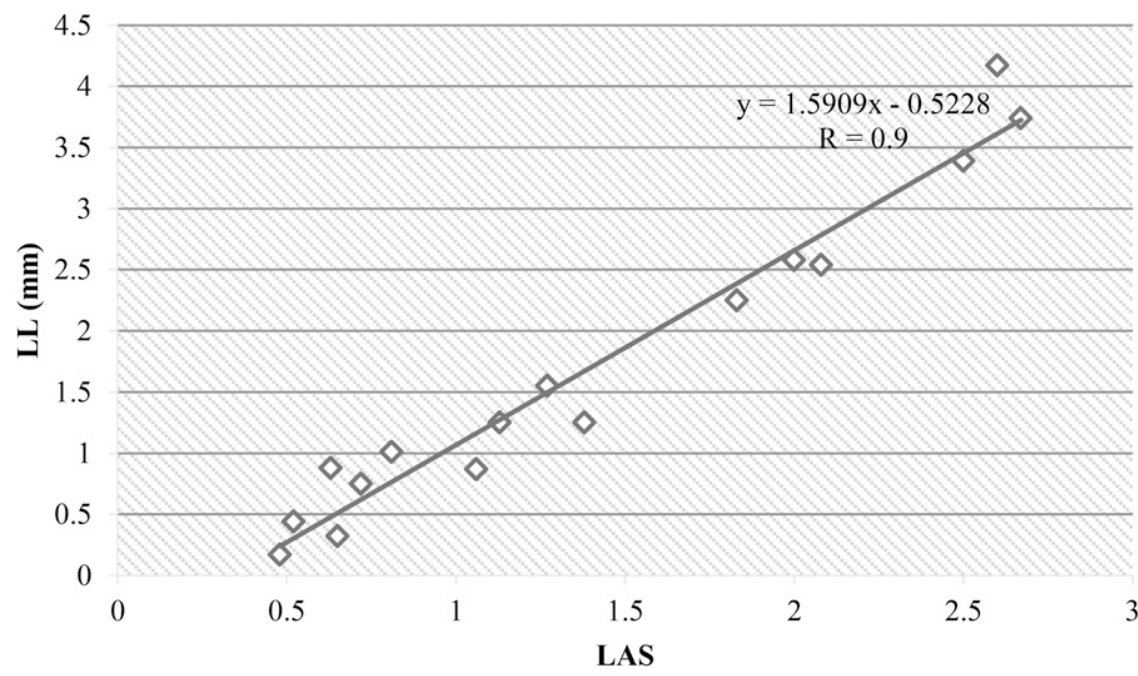

Fig. 2. Correlation of leaf area with symptoms (LAS) and lesion length (LL) measurements of partial resistance after infection with race 8 of Diplocarpon rosae with the detached leaf assay method.

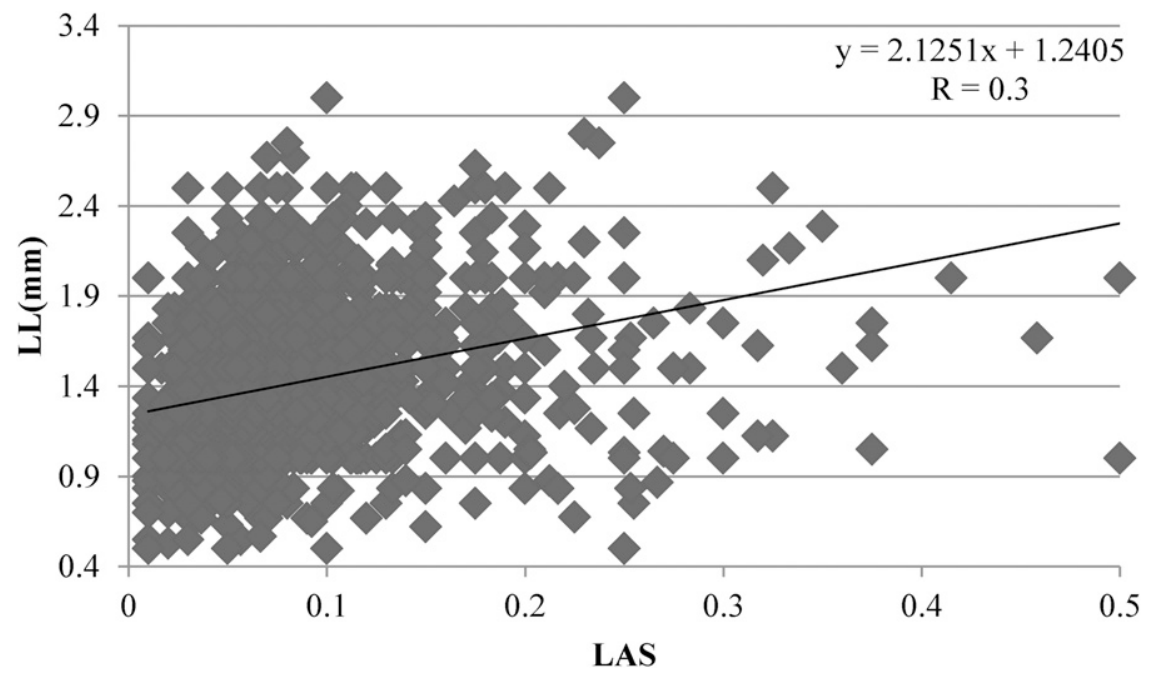

Fig. 3. Correlation of the partial resistance to black spot race 8 as measured by leaf area with symptoms (LAS) and lesion length (LL) in detached leaf assays among individual seedlings of 15 diploid rose progenies.
A.

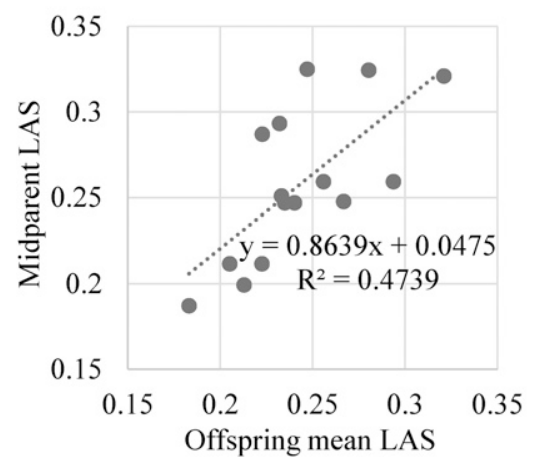

B.

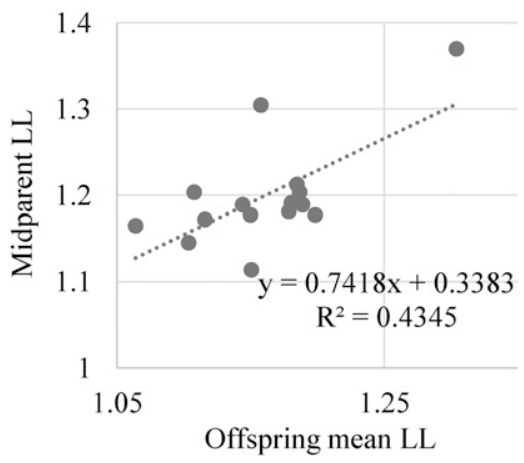

Fig. 4. The slope of offspring-midparent regressions estimates the narrow-sense heritability of 15 diploid populations measured by (A) leaf area with symptoms (LAS) and (B) lesion length (LL) from detached leaf assay inoculated by race 8 of Diplocarpon rosae with $R^{2}$ indicating the fitness of the regression. Original data were transformed using a square root. be 0.28 and 0.43 for LAS and LL, respectively, indicating this partial resistance trait is moderately heritable. The parental variance for LAS and LL account for $24 \%$ and $34 \%$ of the variance, while the progeny variance for LAS and LL accounts for $61 \%$ and $45 \%$ of total genetic variance, respectively, indicating important nonadditive genetic effects. In contrast, the narrow-sense heritability estimation using the offspring-midparent regression approach was 0.86 and 0.74 for LAS and $\mathrm{LL}$, respectively. The fitness of the regressions $\left(R^{2}\right)$ of LAS and LL was calculated as 0.47 and 0.43 , respectively, indicating a fairly good estimation of the midparent and offspring performances (Fig. 4).

\section{Discussion}

Artificial inoculation on parental germplasm. From this project, several cultivars (RF, Cal, SC, VS, and $\mathrm{OH}$ ) were rated as very susceptible to black spot. Interestingly, the breeding line $\mathrm{J} 3-6$, which is derived from the wild species RW and has a high level of partial resistance to black spot, had greater defoliation under WPI than the other resistant lines (Table 2). In contrast, Cal, a susceptible material based on field observation, showed no defoliation under WPI. It is possible that different resistant mechanisms occurred in the host plants.

Artificial inoculation results indicated that DLA could distinguish the performance of the genotypes better than WPI, and the LL and LAS of DLA were well correlated as previously reported by Xue and Davidson (1998). Our results also confirm previous studies (Whitaker and Hokanson, 2009b) that with the DLA approach, it is easier to create a uniform humid environment and it requires less input of time and facilities as compared with the WPI. The DLA is more appropriate for the phenotyping of large populations and cultivar collections. However, as LAS and LL data generated from WPI were well correlated with LAS and LL data generated from DLA (Table 3), WPI could be used as a complementary characterization method to DLA for those genotypes whose leaves degraded easily.

Genetic variances calculated from the mixed model (both LAS and LL) indicated that the additive variances explained $24 \%$ to $34 \%$ of the total variances, which is lower than that explained by nonadditive variances (45\% to $61 \%$ ) (Table 4$)$. In contrast, the midparent-progeny mean regression indicated that both measures were mainly additive in inheritance with heritability estimates of $0.74-0.86$. The normal breeding approach for rose, a clonally propagated crop, is recurrent mass selection. Thus, selection is based on the phenotype of the individual seedlings with the best phenotypes being used as parents for the next generation. This is an efficient approach for traits with high narrow-sense heritability. The narrow-sense heritability estimates for LL and LAS ranged by estimation approach REML $\left(h^{2}=0.28-0.43\right)$ and midparent regression $\left(h^{2}=0.74-0.86\right)$, 
Table 4. Variance component ${ }^{\mathrm{z}}$ distribution $(\%)^{\mathrm{y}}$ and estimated heritability ${ }^{\mathrm{x}}$ of 15 diploid rose populations measured by square-roottransformed leaf area with symptoms (LAS) and lesion length (LL) from detached leaf assay inoculated by race 8 of Diplocarpon rosae.

\begin{tabular}{lcccc}
\hline Components & $\sigma_{\mathrm{A}}^{2}(\%)$ & $\sigma_{\mathrm{D}}^{2}(\%)$ & $\sigma_{\mathrm{P}}^{2}(\%)$ & $h^{2}$ \\
\hline LAS & 23.9 & 61.1 & 85.0 & 0.28 \\
LL & 33.9 & 45.3 & 79.2 & 0.43 \\
\hline
\end{tabular}

${ }^{\mathrm{z}} \sigma_{\mathrm{P}}^{2}=$ Phenotypic variances based on populations of individuals; $\sigma_{\mathrm{A}}^{2}=$ additive variances based on variances of parents; $\sigma_{D}^{2}=$ nonadditive variances based on variance of progeny.

${ }^{\mathrm{y}}$ Percent of total variances $=$ percentage of total genetic variances caused by $\sigma_{A}^{2}, \sigma_{D}^{2}$, and $\sigma_{P}^{2}$.

${ }^{\mathrm{x}}$ Narrow-sense heritability $=$ ratio of additive genetic variance to total phenotypic variance; $h^{2}=\sigma_{\mathrm{A}}^{2} / \sigma_{\mathrm{P}}^{2}$.

indicating this approach should be moderately to highly effective. Nevertheless, if the nonadditive genetic variance is as large as the additive genetic variance as indicated by the REML analysis, the progeny performance of specific parents should also be factored into the choice of parents in population creation. From a complete factorial mating design of partially resistant and susceptible roses conducted by Whitaker and Hokanson (2009a), within-family variances are much lower than that of between-family variances. Therefore, selection for certain families (generated from specific parental combinations) followed by backcrossing to the parents with more advanced ornamental traits was suggested for future breeding as an efficient selection/breeding approach.

Different results of narrow-sense heritability estimated from genetic variances and offspring-midparent regression might due to the structure of hybrid populations as the incomplete diallel mating design used in this study reduces the power of estimating genetic variances. In either case, the data indicate that it should be possible to develop a rose with stable and high resistance to black spot based on partial resistance derived from RW.

\section{Literature Cited}

AmericanHort. 2014. Rose rosette disease targeted in 2014. 28 Apr. 2014. <http://americanhort. theknowledgecenter.com/AmericanHortNews/ index.cfm?view $=$ detail $\&$ colid $=147 \&$ cid $=421$ $\&$ mid $=6001>$.

Blechert, O. and T. Debener. 2005. Morphological characterization of the interaction between Diplocarpon rosae and various rose species. Plant Pathol. 54:82-90.

Byrne, D.H. 2015. Advances in rose breeding and genetics in North America. Acta Hort. 1064:89-98.
Byrne, D.H., N. Anderson, M. Orwat, and V. Soules. 2010. Field assessment of black spot resistance in roses in a hot humid climate. Acta Hort. 870:115-120.

Carlson-Nilsson, B.U. 2002. Variation in Rosa with emphasis on the improvement of winter hardiness and resistance to Marssonina rosae (Black spot). Swedish Univ. of Agr. Sci., Uppsala, PhD Diss.

Connor, A.M., M.J. Stephens, H.K. Hall, and P.A. Alspach. 2005. Variation and heritabilities of antioxidant activity and total phenolic content estimated from a red raspberry factorial experiment. J. Amer. Soc. Hort. Sci. 130:403411.

Debener, T. and D. Byrne. 2014. Disease resistance breeding in rose: Current status and potential of biotechnological tools. Plant Sci. 228:107-117.

Dieters, M.J., T.L. White, R.C. Littell, and G.R. Hodge. 1995. Application of approximate variances of variance components and their ratios in genetic tests. Theor. Appl. Genet. 91:15-24.

Falconer, D.S. and T.F.C. Mackay. 1996. Introduction to quantitative genetics. 4th ed. Prentice Hall, New York, NY.

Gachomo, E.W., H.W. Dehne, and U. Steiner. 2006. Microscopic evidence for the hemibiotrophic nature of Diplocarpon rosae, cause of black spot disease of rose. Physiol. Mol. Plant Pathol. 69:86-92.

Gudin, S. 2000. Rose: Genetics and breeding. Plant Breeding Rev. 17:159-189.

Hallauer, A.R., M.J. Carena, and J.B. Miranda Filho. 2010. Quantitative genetics in maize breeding. Springer, New York, NY.

Hattendorf, A., M. Linde, L. Mattiesch, T. Debener, and H. Kaufmann. 2004. Genetic analysis of rose resistance genes and their localisation in the rose genome. Acta Hort. 651:123-130.

Holland, J.B., W.E. Nyquist, and C.T. CrevantesMartinez. 2003. Estimating and interpreting heritability for plant breeding: An update. Plant Breeding Rev. 22:9-112.

Horst, R.K. and R.A. Cloyd. 2007. Compendium of rose diseases and pests. 2nd ed. Amer. Phytopathol. Soc., Saint Paul, MN.

Hutton, S. 2012. The future of the rose industry. Amer. Rose 41:36-37.

Johansson, M., E. Kronestedt-Robards, and A. Robards. 1992. Rose leaf structure in relation to different stages of micropropagation. Protoplasma 166:165-176.

Krüssmann, G. 1981. The complete book of roses. Timber Press, Portland, OR.

Littell, R.C., G.A. Milliken, W.W. Stroup, and R.D. Wolfinger. 1996. SAS system for mixed models. SAS Institute, Inc., Cary, NC.

Marriott, M. 2003. History of roses in cultivation/ modern (Post-1800), p. 402-409. In: A.V Roberts, T. Debener, and S. Gudin (eds.). Encyclopedia of rose science. Elsevier, Oxford, UK.

Nauta, M.M. and B.M. Spooner. 2000. British Dermateaceae: 4B. Dermateoideae gerna B-E. Mycologist 14:21-28.

Noack, R. 2003. Breeding/selection strategies for disease and pest resistance, p. 49-55. In: A.V.
Roberts, T. Debener, and S. Gudin (eds.). Encyclopedia of rose science. Elsevier, Oxford, UK.

Palmer, J.G., P. Seminuk, and R.N. Stewart. 1966. Roses and blackspot. II. Seasonal variation in host susceptibility and decline of virulence in culture of conidia from Diplocarpon rosae. Phytopathology 56:12831286.

Parlevliet, J.E. 1981. Race-non-specific disease resistance, p. 47-54. In: J.F. Jenkyn and R.T. Plumb (eds.). Strategies for the control of cereal disease. Blackwell, Oxford, UK.

Razali, N.M. and Y.B. Wah. 2011. Power comparisons of Shapiro-Wilk, Kolmogorov-Smirnov, Lilliefors and Anderson-Darling tests. J. Stat. Modeling Analytics 2:21-33.

Shepherd, R.E. 1954. History of the rose. Macmillan, New York, NY.

Shupert, D. 2005. The inheritance of several traits in three diploid interspecific rose populations. Texas A\&M Univ., College Station, MS Thesis.

von Malek, B. and T. Debener. 1998. Genetic analysis of resistance to blackspot (Diplocarpon rosae) in tetraploid roses. Theor. Appl. Genet. 96:228-231.

Waliczek, T.M., D.H. Byrne, and D. Holeman. 2015. Growers' and consumers' knowledge, attitudes and opinions regarding roses available for purchase. Acta Hort. 1064:235240 .

Whitaker, V.M. and S.C. Hokanson. 2009a. Partial resistance to black spot disease in diploid and tetraploid roses: General combining ability and implications for breeding and selection. Euphytica 169:421-429.

Whitaker, V.M. and S.C. Hokanson. 2009b. Breeding roses for disease resistance, p. 277-324. In: J. Janick (ed.). Plant breeding reviews. Vol. 31. Wiley, New York, NY.

Whitaker, V.M., J.M. Bradeen, T. Debener, A. Biber, and S.C. Hokanson. 2010a. Rdr3, a novel locus conferring black spot disease resistance in tetraploid rose: Genetic analysis, LRR profiling, and SCAR marker development. Theor. Appl. Genet. 120:573585 .

Whitaker, V.M., T. Debener, A.V. Roberts, and S.C. Hokanson. 2010b. A standard set of host differentials and unified nomenclature for an international collection of Diplocarpon rosae races. Plant Pathol. 59:745-752.

Xue, A.G. and C.G. Davidson. 1998. Components of partial resistance to black spot disease (Diplocarpon rosae Wolf) in garden roses. HortScience 33:96-99.

Yokoya, K., K. Kandasamy, S. Walker, Z. Mandegaran, and A.B. Roberts. 2000. Resistance of roses to pathotypes of Diplocarpon rosae. Ann. Appl. Biol. 136:15-20.

Zlesak, D.C., V.M. Whitaker, S. George, and S.C. Hokanson. 2010. Evaluation of roses from the Earth-Kind ${ }^{\circledR}$ Trials: Black spot (Diplocarpon rosae Wolf) resistance and ploidy. HortScience 45:1779-1787. 